\title{
A semi-flexible aminotriazine-based bis-methylpyridine ligand for the design of nickel(II) spin clusters $\uparrow$
}

3044

Received 15th October 2013,

Accepted 30th October 2013

DOI: $10.1039 / c 3 d t 52903 g$

www.rsc.org/dalton

The self-assembly of a semi-flexible aminotriazine-based bismethylpyridine ligand, $N^{2}, N^{2}$-dibenzyl- $N^{4}, N^{6}$-di(pyridylmethyl)1,3,5-triazine-2,4,6-triamine $\left(\mathrm{H}_{2} \mathrm{~L}\right)$, with $\mathrm{NiCl}_{2}$ and $\mathrm{NiBr}_{2}$ afforded two new nickel(II) clusters, $\left(\mathrm{H}_{2} \mathrm{NMe}_{2}\right)_{2}\left[\mathrm{Ni}_{5}(\mathrm{OH})_{2}\left(\mathrm{H}_{2} \mathrm{~L}\right)_{2} \mathrm{Cl}_{10}\right]$ (1) and $\left[\mathrm{Ni}_{6}(\mathrm{OH})_{2}\left(\mathrm{H}_{2} \mathrm{~L}\right)_{2} \mathrm{Br}_{10}(\mathrm{THF})_{2}\right]$ (2) showing a high spin ground state of $S=3$.

The development of new molecule-based magnets is an important research topic in the fields of chemistry and physics, due to their impressive structural diversity and intriguing physical properties as well as complicated magneto-structural correlations. ${ }^{1}$ One of the major challenges in the area of molecular magnetism is the construction of a polynuclear metal cluster that exhibits interesting magnetic properties, such as the highspin ground state and/or single-molecule magnet (SMM) behavior. $^{2-5}$ For the preparation of such metal clusters, using a polychelating ligand with an unused arm or a donor site has been recognized. ${ }^{6,7}$ An alternative preparation method is to utilize the flexidentate behavior of a multidentate ligand and judicial choice of bridging ligands, such as carboxylate and azide. $^{8,9}$ Among the bridging ligands, halide ions have been known for their versatile bridging coordination modes that generate polymeric compounds. ${ }^{10}$

Poly-pyridyl ligands had a major impact in the field of supramolecular chemistry for decades, which have led to a variety of metal/ligand supramolecular ensembles to be obtained such as double and triple helices, grids, ladders, and so forth. ${ }^{11}$ However, the flexible poly-pyridyl ligands are rarely exploited in the formation of polynuclear metal clusters;

\footnotetext{
${ }^{a}$ Department of Chemistry, Tunghai University, Taichung 407, Taiwan. E-mail: ciyang@thu.edu.tw; Fax: +886-4-23590426

${ }^{b}$ Division of Applied Chemistry, Graduate School of Engineering, Osaka University, 2-1 Yamada-oka, Suita, 565-0871, Japan

${ }^{c}$ Department of Applied Chemistry, National Chi Nan University, Nantou 545, Taiwan.E-mail: lilai@ncnu.edu.tw

$\dagger$ Electronic supplementary information (ESI) available: Detailed experimental procedures, additional crystallographic diagrams and magnetic diagram. CCDC 947250 and 947251. For ESI and crystallographic data in CIF or other electronic format see DOI: $10.1039 / \mathrm{c} 3 \mathrm{dt} 52903 \mathrm{~g}$
}

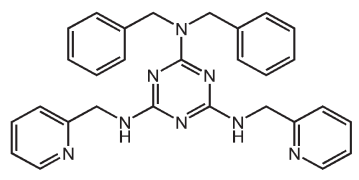

Scheme 1 Schematic representation of $\mathrm{H}_{2} \mathrm{~L}$ ligand.

especially the resulting structures may potentially exhibit interesting magnetic properties.

We herein report the self-assembly of two Ni(II) clusters, $\left(\mathrm{H}_{2} \mathrm{NMe}_{2}\right)_{2}\left[\mathrm{Ni}_{5}(\mathrm{OH})_{2}\left(\mathrm{H}_{2} \mathrm{~L}\right)_{2} \mathrm{Cl}_{10}\right] \quad$ (1) and $\left[\mathrm{Ni}_{6}(\mathrm{OH})_{2}\left(\mathrm{H}_{2} \mathrm{~L}\right)_{2}-\right.$ $\left.\mathrm{Br}_{10}(\mathrm{THF})_{2}\right]$ (2), using a semi-flexible aminotriazine-based bismethylpyridine ligand, $N^{2}, N^{2}$-dibenzyl- $N^{4}, N^{6}$-di(pyridylmethyl)-1,3,5-triazine-2,4,6-triamine $\left(\mathrm{H}_{2} \mathrm{~L}\right)$. The designed ligand, $\mathrm{H}_{2} \mathrm{~L}$ (Scheme 1), contains an aminotriazine ring and two flexible methylpyridine arms, which could chelate metal ions into clusters 1 and 2, exhibiting an $S=3$ spin ground state arising from the uncanceled spin arrangement of the antiferro- and ferromagnetic interactions in $\mathbf{1}$ and ferromagnetic interaction in 2 , respectively.

$\mathrm{X}$-ray crystal structure analysis showed that $\mathbf{1}$ and $2 \$$ crystallize in the monoclinic space groups $P 2_{1} / n$ and in the triclinic space groups $P \overline{1}$, respectively. In complex $\mathbf{1}$, the geometry of the centrosymmetric $\mathrm{Ni}^{\mathrm{II}}$ cluster can be described as two corner-sharing $\mu_{3}-\mathrm{OH}$-centred $\mathrm{Ni}^{\mathrm{II}}{ }_{3}$ triangles with bowtie topology (Fig. 1). Two $\mathrm{H}_{2} \mathrm{~L}$ groups connect the central $\mathrm{Ni}^{\mathrm{II}}$ atom (Ni1) and two peripheral metal ions in the two sides of a bow tie (Ni2 and Ni3) in a $\mu_{3}-\mathrm{H}_{2} \mathrm{~L}-\kappa^{5}-N, N^{\prime}: N^{\prime \prime}: N^{\prime \prime \prime}, N^{\prime \prime \prime \prime}$ coordination mode, in which two methylpyridine groups exhibit in a transconformation. The base (Ni2 $\cdots \mathrm{Ni} 3)$ of each triangle is bridged by two $\mu_{2}-\mathrm{Cl}^{-}$anions. The $\mu_{3}-\mathrm{OH}^{-}$group links the central Ni1 to the two peripheral metal ions on either side of the molecule and the $\mathrm{O}$ atom of $\mathrm{OH}^{-}$lie out of the plane of the $\mathrm{Ni}_{3}$ triangle about $0.402 \AA$ A. Peripheral ligations around each Ni centers are completed by terminal $\mathrm{Cl}^{-}$anions.

The structure of complex 2 reveals a dimer of $\left[\mathrm{Ni}^{\mathrm{II}}{ }_{3}\left(\mu_{3}-\mathrm{OH}\right)\right.$ $\left.\left(\mu_{3}-\mathrm{Br}\right)\left(\mu_{2}-\mathrm{Br}\right)_{3}\right]^{+}$core which is connected by two bis-chelating $\mathrm{H}_{2} \mathrm{~L}$ ligands (Fig. 2). The structure $\left[\mathrm{Ni}_{3}{ }_{3}\left(\mu_{3}-\mathrm{OH}\right)\left(\mu_{3}-\mathrm{Br}\right)\left(\mu_{2}-\mathrm{Br}\right)_{3}\right]^{+}$ adopts a near-equilateral $\mathrm{Ni}_{3}{ }_{3}$ triangle core, which is bonded 


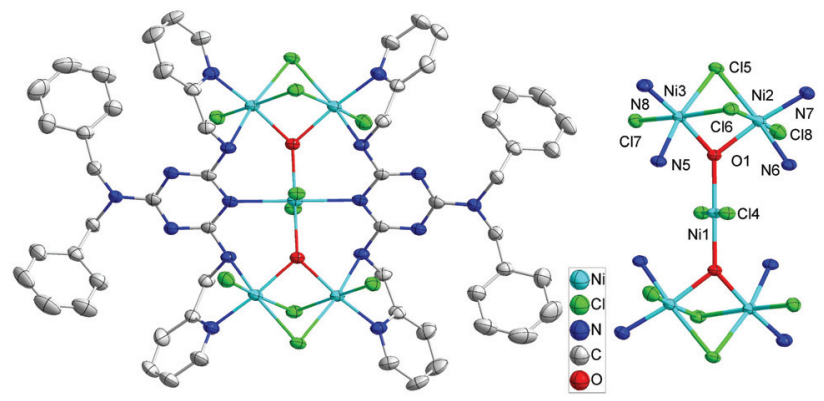

Fig. 1 Crystal structure of the anion complex 1 (left) and its $\mathrm{Ni}_{5}{ }_{5}$ core structure (right). The $\mathrm{Me}_{2} \mathrm{NH}_{2}$ cations and $\mathrm{H}$ atoms were omitted for clarity.

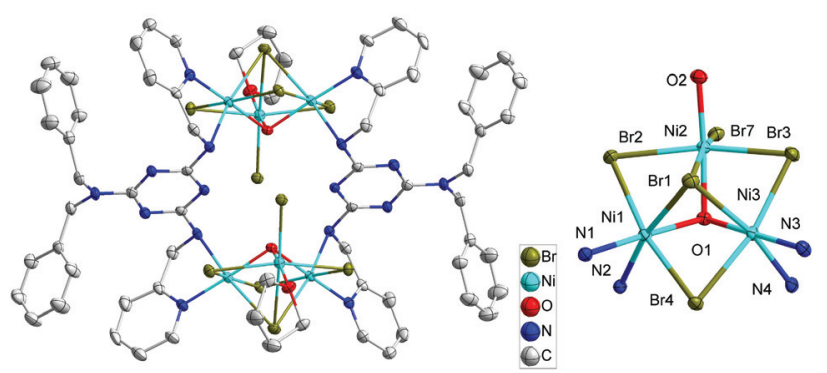

Fig. 2 Crystal structure of the complex 2 (left) and its $\mathrm{Ni}_{3}{ }_{3}$ core structure (right). The $\mathrm{H}$ atoms were omitted for clarity.

by a $\mu_{3}$-oxide (O1) and a $\mu_{3}-\mathrm{Br}^{-}$(Br1) on both sides of the central planar where the central $\mathrm{OH}^{-}$and $\mathrm{Br}^{-}$bridges are located 0.902 and $2.056 \AA$ above the $\mathrm{Ni}_{3}$ plane. Each base of the $\mathrm{Ni}^{\mathrm{II}}{ }_{3}$ triangle is connected by $\mu_{2}-\mathrm{Br}^{-}$anions $(\mathrm{Br} 2-\mathrm{Br} 4)$. Two $\mathrm{H}_{2} \mathrm{~L}$ ligands in complex 2 exhibit a $\mu_{2}-\mathrm{H}_{2} \mathrm{~L}-\kappa^{4}-N, N^{\prime}: N^{\prime \prime}, N^{\prime \prime \prime}$ coordination mode with trans-conformation of their two methylpyridine groups and connects the two $\mathrm{Ni}_{3}$ triangles into a hexanuclear dimer of $\mathrm{Ni}_{3}$ structure. Peripheral ligations around each Ni2 centers are ended by one terminal $\mathrm{Br}^{-}$anion and one THF molecule.

The solid-state, variable-temperature magnetic susceptibility measurements were performed on microcrystalline samples of complexes 1 and 2 in the $2-300 \mathrm{~K}$ range in a 1 kOe magnetic field, which was suspended in eicosane to prevent torquing.

For complex 1, the $\chi_{\mathrm{M}} T$ value of $6.01 \mathrm{~cm}^{3} \mathrm{~K} \mathrm{~mol}^{-1}$ at $300 \mathrm{~K}$ decreases gradually with decreasing temperature in the range of 300 to $70 \mathrm{~K}$, then abruptly increases, reaching a maximum of $7.05 \mathrm{~cm}^{3} \mathrm{~K} \mathrm{~mol}^{-1}$ at $10 \mathrm{~K}$, and decreases to $4.38 \mathrm{~cm}^{3} \mathrm{~K}$ $\mathrm{mol}^{-1}$ at $2 \mathrm{~K}$ (Fig. 3). The change in $\chi_{\mathrm{M}} T$ value indicates that antiferromagnetic dominated in the $\mathrm{Ni}_{5}$ unit with a non-canceled spin ground state and the $\chi_{\mathrm{M}} T$ value at $10 \mathrm{~K}$ is consistent with $S=3(g=2.2)$. Below $10 \mathrm{~K}$, the $\chi_{\mathrm{M}} T$ values slowly decrease, probably due to weak intermolecular antiferromagnetic interactions, zero field splitting and/or small anisotropy.

In order to understand the magnetic coupling of complex $\mathbf{1}$, the magnetic susceptibility data were fitted using a $\mathrm{Ni}^{\mathrm{II}}$ Heisenberg-van Vleck model. Based on the structure analysis, the number of magnetic interactions can be reduced significantly: $J_{1}$ for $\mathrm{Ni}^{\mathrm{II}} \cdots \mathrm{Ni}^{\mathrm{II}}$ through one $\mu_{3}-\mathrm{OH}$ and one $\mathrm{H}_{2} \mathrm{~L}$

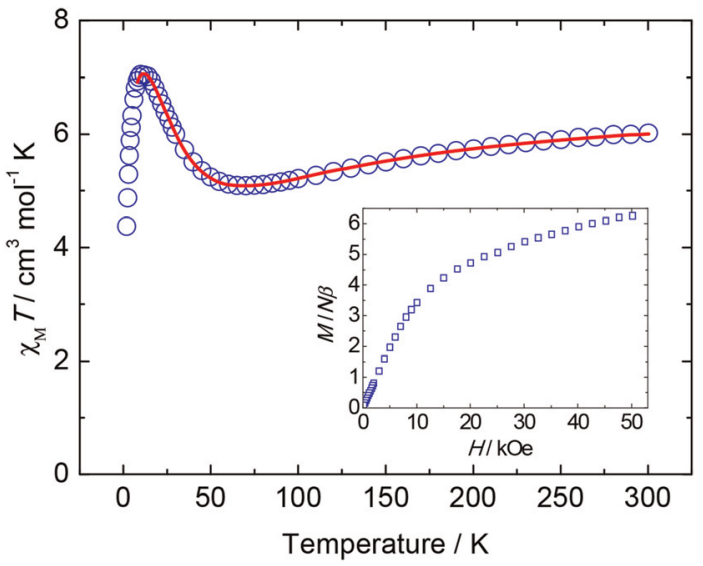

Fig. 3 Plots of $\chi_{\mathrm{M}} T$ versus $T$ for 1 in an applied field of $1 \mathrm{kOe}$ from 2.0 to $300 \mathrm{~K}$. The solid line represents a least-squares fit of the data (see text). The inset shows a $2 \mathrm{~K}$ magnetization isotherm collected between 0 and $50 \mathrm{kOe}$.

bridgings and $J_{2}$ for $\mathrm{Ni}^{\mathrm{II}} \cdots \mathrm{Ni}^{\mathrm{II}}$ through one $\mu_{3}-\mathrm{OH}^{-}$and two $\mu_{2}-\mathrm{Cl}^{-}$bridges (see Fig. S5 in the ESI $\dagger$ ), hence the Hamiltonian can be written as:

$$
H=-2 J_{1}\left(S_{1} S_{2}+S_{1} S_{3}+S_{1} S_{4}+S_{1} S_{5}\right)-2 J_{2}\left(S_{2} S_{3}+S_{4} S_{5}\right)
$$

The $\chi_{\mathrm{M}} T$ data could be well fitted by this Heisenberg-van Vleck model with the addition of an intermolecular interaction by the mean-field approximation $\left(z J^{\prime}\right)$. The results from fitting the experimental data are shown as solid lines in Fig. 3, with final parameters being $g=2.30, J_{1}=-11.7 \mathrm{~cm}^{-1}, J_{2}=3.5 \mathrm{~cm}^{-1}$ and $z J^{\prime}=-0.10 \mathrm{~cm}^{-1}$. This set of parameters leads to the conclusion that the ground state is $S_{\mathrm{T}}=3$ and the first excited state is $S=2$ at $24 \mathrm{~cm}^{-1}$ above the ground state (Fig. S6†). The estimated values, for the intracluster magnetic exchange interactions, indicate that the antiferro- and ferromagnetic interactions are provided within the $\mathrm{Ni}^{\mathrm{II}}{ }_{5}$ cluster in $\mathbf{1}$, and are associated with an $S=3$ spin ground state. Both interactions $\left(J_{1}\right.$ and $J_{2}$ ) are close to the reported exchange interactions of $\mathrm{Ni}^{\mathrm{II}} \cdots \mathrm{Ni}^{\mathrm{II}}$ through the similar pathways. ${ }^{12}$ The magnetization curve recorded at $2 \mathrm{~K}$ of complex 1 shows a continuous increase up to the saturation value of $6.3 N \beta$ (Fig. 3 inset), which corresponds well to a ground-state spin $S=3$, in agreement with the $\chi_{\mathrm{M}} T$ data. However, this magnetization curve cannot be nicely fitted by the Brillouin equation for $S=3$, probably due to the presence of intermolecular interaction, zero field splitting and/or anisotropy.

For complex 2, the value of $\chi_{\mathrm{M}} T$ increases steadily from $4.24 \mathrm{~cm}^{3} \mathrm{~mol}^{-1} \mathrm{~K}$ at $300 \mathrm{~K}$ as the temperature decreases to reach a maximum of $6.03 \mathrm{~cm}^{3} \mathrm{~mol}^{-1} \mathrm{~K}$ at $18 \mathrm{~K}$, and then decreases to $1.00 \mathrm{~cm}^{3} \mathrm{~mol}^{-1} \mathrm{~K}$ at $2.0 \mathrm{~K}$ (Fig. 4). The $\chi_{\mathrm{M}} T$ value at $300 \mathrm{~K}$ is slightly larger than $4.00 \mathrm{~cm}^{3} \mathrm{~mol}^{-1} \mathrm{~K}$, the expected value for a $\mathrm{Ni}^{\mathrm{II}}{ }_{3}$ complex with noninteracting metal centers with $g=2.3$. This behavior clearly indicates the ferromagnetic coupling within complex 2 and the decrease in $\chi_{\mathrm{M}} T$ at low temperature $(<28 \mathrm{~K})$ is likely due to the intermolecular $\left(\mathrm{Ni}_{3} \cdots \mathrm{Ni}_{3}\right)$ interaction, the Zeeman effect or zero-field splitting 


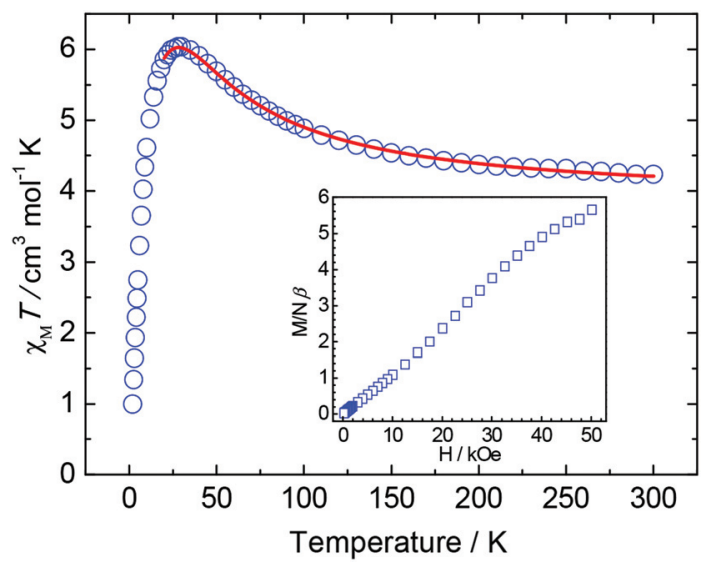

Fig. 4 Plots of $\chi_{M} T$ versus $T$ for 2 in an applied field of $1 \mathrm{kOe}$ from 2.0 to $300 \mathrm{~K}$. The solid line represents a least-squares fit of the data (see text). The inset shows a $2 \mathrm{~K}$ magnetization isotherm collected between 0 and $50 \mathrm{kOe}$.

in the ground state. In order to describe the coupling within the cluster, the magnetic susceptibility data were fitted using a $\mathrm{Ni}^{\mathrm{II}}{ }_{3}$ Heisenberg-van Vleck model: $H=-2 J\left(S_{1} S_{2}+S_{2} S_{3}+S_{1} S_{3}\right)$ with an interunit interaction by the mean-field approximation $\left(\mathrm{z} J^{\prime}\right)$ (Fig. S7 $\dagger$ ). The data below $20 \mathrm{~K}$ were omitted in the fitting, because zero-field splitting and Zeeman effect likely dominate in this temperature range. The fitting result of dc data in 1 kOe gave the best fit parameters of $g=2.26, J=8.10 \mathrm{~cm}^{-1}$ and $z J^{\prime}=-0.50 \mathrm{~cm}^{-1}$. This set of parameters gives the ground state of $S_{\mathrm{T}}=3$ and the first excited state $S=2$ at $-48 \mathrm{~cm}^{-1}$ above the ground state (Fig. S8 $\dagger$ ). Although the magnetic interaction between $\mathrm{Ni}^{\mathrm{II}}$ ions through such bridges (one $\mu_{3}-\mathrm{OH}$, one $\mu_{3}-\mathrm{Br}$ and one $\mu_{2}-\mathrm{Br}$ ) has not been reported in the literature, it is believed that the ferromagnetic interactions ensue from 6-coordinate geometry and the $\mathrm{Ni}-\mathrm{X}-\mathrm{Ni}$ bridging angles close to $90^{\circ} .{ }^{13}$ The magnetization curve recorded at $2 \mathrm{~K}$ of 2 is shown in Fig. 4 inset, in which the magnetization slowly increases with the increase of field and becomes saturated around $50 \mathrm{kOe}$ with a value of $5.65 \mathrm{~N} \beta$. The less rapid saturation of magnetization at low field may result from the antiferromagnetic interaction of $\mathrm{Ni}_{3} \cdots \mathrm{Ni}_{3}$ interunit and the saturation magnetization value corresponds well to a groundstate spin $S=3$, in agreement with the $\chi_{\mathrm{M}} T$ data. Again, this magnetization curve cannot be well fitted by the Brillouin equation for $S=3$, due to the presence of intermolecular interaction and/or zero field splitting.

To investigate whether 1 and 2 might be a SMM, ac susceptibility measurements were performed with a zero applied dc field. Representative results for $\mathbf{1}$ and $\mathbf{2}$ are shown in Fig. S9 and S10. $\dagger$ At lower temperatures, the in-phase signal $\left(\chi_{\mathrm{M}}{ }^{\prime} T\right)$ increases to $\sim 6.8$ and $6.5 \mathrm{~cm}^{3} \mathrm{~K} \mathrm{~mol}^{-1}$ for $\mathbf{1}$ and 2, respectively, confirming the spin ground state of $S=3$ for both complexes. For complex 1, a weak $\chi_{\mathrm{M}}{ }^{\prime \prime}$ signal appears below $5 \mathrm{~K}$, which is indicative of a slow magnetic relaxation within $\mathbf{1}$. However, the peak maxima clearly lie in the temperatures below $1.8 \mathrm{~K}$, the operating limit of our instrument. These data thus suggest that compound 1 indeed exhibits a slow magnetic relaxation or long-range magnetic ordering at temperatures below $1.8 \mathrm{~K}$. In contrast, the complex 2 shows no SMM behavior from the absence of $\chi_{\mathrm{M}}{ }^{\prime \prime}$ signal.

In conclusion, the use of semi-flexible aminotriazine-based bis-methylpyridine ligands $\left(\mathrm{H}_{2} \mathrm{~L}\right)$ has allowed the access of two novel Ni clusters with interesting magnetic properties. The $\mathrm{H}_{2} \mathrm{~L}$ ligand represents a 'proof of feasibility' for the belief that such ligands may provide a rich source of new transition-metal clusters. Further studies are in progress.

\section{Notes and references}

$\ddagger$ The complexes analyzed as (C, H, N) 1, calcd (found): C, 42.52 (42.17); H, 4.26 (4.79); N, 14.40 (14.35)\% and 2, calcd (found): C, 34.37 (34.03); H, 3.23 (3.34); N, 9.72 (9.72)\%. Crystal-structure data for $1, \mathrm{C}_{62} \mathrm{H}_{70} \mathrm{Cl}_{10} \mathrm{~N}_{18} \mathrm{Ni}_{5} \mathrm{O}_{2}, M=1747.31$, monoclinic, $P 2_{1} / n, a=15.7038(12) \AA, b=9.9564(7) \AA ⿻$, $c=23.8274(18) \AA, \beta=$ $93.4680(10)^{\circ}, V=3718.7(5) \AA^{3}, T=150(2) \mathrm{K}, Z=2 .\left(R_{\text {int }}=0.0426\right), 8215$ parameters, $R\left(R_{\mathrm{w}}\right)=0.0382(0.0865)$ with $[I>2 \sigma(I)]$ and for $2, \mathrm{C}_{66} \mathrm{H}_{74} \mathrm{Br}_{10} \mathrm{~N}_{16} \mathrm{Ni}_{6} \mathrm{O}_{4}$, $M=2306.56$, triclinic, $P \overline{1}, a=11.9623(7) \AA, b=13.3874(8) \AA, c=14.2964(9) \AA, \alpha=$ $65.3520(10)^{\circ}, \beta=72.9400(10)^{\circ}, \gamma=75.1400(10)^{\circ}, V=1965.5(2) \AA^{3}, T=150(2) \mathrm{K}$, $Z=1$. $\left(R_{\text {int }}=0.0291\right)$, 9051 parameters, $R\left(R_{\mathrm{w}}\right)=0.0256(0.0481)$ with $[I>2 \sigma(I)]$.

1 Magnetism: Molecules to. Materials, ed. J. S. Miller and M. Drillon, Wiley-VCH, Weinheim, Germany, 2001-2004, vol. I-V.

2 (a) G. Christou, D. Gatteschi, D. N. Hendrickson and R. Sessoli, MRS Bull., 2000, 25, 66-71; (b) R. Sessoli, H.-L. Tsai, A. R. Schake, S. Wang, J. B. Vincent, K. Folting, D. Gatteschi, G. Christou and D. N. Hendrickson, J. Am. Chem. Soc., 1993, 115, 1804-1816; (c) A. Caneschi, D. Gatteschi, R. Sessoli, A. L. Barra, L. C. Brunel and M. Guillot, J. Am. Chem. Soc., 1991, 113, 5873-5874; (d) M. Nakano and H. Oshio, Chem. Soc. Rev., 2011, 40, 3239-3248.

3 (a) R. Sessoli, D. Gatteschi, A. Caneschi and M. A. Novak, Nature, 1993, 365, 141-143; (b) D. Gatteschi, R. Sessoli and A. Cornia, Chem. Commun., 2000, 725-732; (c) Z. Sun, C. M. Grant, S. L. Castro, D. N. Hendrickson and G. Christou, Chem. Commun., 1998, 721-722; (d) E. C. Yang, D. N. Hendrickson, W. Wernsdorfer, M. Nakano, L. N. Zakharov, R. D. Sommer, A. L. Rheingold, M. Ledezma-Gairaud and G. Christou, J. Appl. Phys., 2002, 91, 7382-7384; (e) C.-I. Yang, W. Wernsdorfer, Y.-J. Tsai, G. Chung, T.-S. Kuo, G.-H. Lee, M. Shieh and H.-L. Tsai, Inorg. Chem., 2008, 47, 1925-1939.

4 (a) G. Christou, Polyhedron, 2005, 24, 2065-2075; (b) D. Gatteschi, R. Sessoli and J. Villain, Molecular Nanomagnets, Oxford University Press, New York, 2006; (c) G. Aromí and E. K. Brechin, Struct. Bonding, 2006, 122, 1 and references therein.

5 (a) T. N. Nguyen, W. Wernsdorfer, K. A. Abboud and G. Christou, J. Am. Chem. Soc., 2011, 133, 20688-20691; (b) A. Saha, K. A. Abboud and G. Christou, Inorg. Chem., 2011, 50, 12774-12784; (c) Z. Wang, J. Van Tol, T. Taguchi, M. R. Daniels, G. Christou and N. S. Dalal, J. Am. Chem. Soc., 2011, 133, 17586-17589. 
6 (a) A. M. Ako, I. J. Hewitt, V. Mereacre, R. Clérac, W. Wernsdorfer, C. E. Anson and A. K. Powell, Angew. Chem., Int. Ed., 2006, 45, 4926-4929; (b) S. S. Tandon, S. D. Bunge, J. Sanchiz and L. K. Thompson, Inorg. Chem., 2012, 51, 3270-3282; (c) Z. E. Serna, M. K. Urtiaga, M. G. Barandika, R. Cortés, S. Martin, L. Lezama, M. I. Arriortua and T. Rojo, Inorg. Chem., 2001, 40, 4550-4555.

7 (a) E. E. Moushi, C. Lampropoulos, W. Wernsdorfer, V. Nastopoulos, G. Christou and A. J. Tasiopoulos, J. Am. Chem. Soc., 2010, 132, 16146-16155; (b) C. C. Stoumpos, O. Roubeau, G. Aromi, A. J. Tasiopoulos, V. Nastopoulos, A. Escuer and S. P. Perlepes, Inorg. Chem., 2010, 49, 359361; (c) M. Murugesu, J. Raftery, W. Wernsdorfer, G. Christou and E. K. Brechin, Inorg. Chem., 2004, 43, 4203-4209; (d) T. C. Stamatatos, C. G. Efthymiou, C. C. Stoumpos and S. P. Perlepes, Eur. J. Inorg. Chem., 2009, 2009, 3361-3391.

8 (a) C. Papatriantafyllopoulou, T. C. Stamatatos, W. Wernsdorfer, S. J. Teat, A. J. Tasiopoulos, A. Escuer and S. P. Perlepes, Inorg. Chem., 2010, 49, 10486-10474; (b) M. Murugesu, M. Habrych, W. Wernsdorfer, K. A. Abboud and G. Christou, J. Am. Chem. Soc., 2004, 126,
4766-4767; (c) T. C. Stamatatos and G. Christou, Inorg. Chem., 2009, 48, 3308-3322.

9 (a) G. Aromí, M. J. Knapp, J.-P. Claude, J. C. Huffman, D. N. Hendrickson and G. Christou, J. Am. Chem. Soc., 1999, 121, 5489-5499; (b) M. Charalambous, E. E. Moushi, C. Papatriantafyllopoulou, W. Wernsdorfer, V. Nastopoulos, G. Christou and A. J. Tasiopoulos, Chem. Commun., 2012, 48, 5410-5412; (c) J. Esteban, L. Alcázar, M. Torres-Molina, M. Monfort, M. Font-Bardia and A. Escuer, Inorg. Chem., 2012, 51, 5503-5505.

10 (a) J.-M. Lehn, Supramolecular Chemistry, Wiley-VCH, New York, 1995; (b) C. Piguet, G. Berbardinelli and G. Hopfgartner, Chem. Rev., 1997, 97, 2005-2062; (c) M. Albrecht, Chem. Rev., 2001, 101, 3457-3498.

11 (a) J. Esteban, P. E. Ruiz, D. M. Font-Bardia, D. T. Calvet and A. Escuer, Chem.-Eur. J., 2012, 18, 3637-3648; (b) P. L. Pawlak, A. Y. S. Malkhasian, B. Sjlivic, M. J. Tiza, B. E. Kucera, R. Loloee and F. A. Chavez, Inorg. Chem. Commun., 2008, 11, 1023-1026.

12 G. N. Newton, H. Sato, T. Shiga and H. Oshio, Dalton Trans., 2013, 42, 6701-6704.

13 A. Bencini and D. Gatteschi, Inorg. Chim. Acta, 1978, 31, 11. 